\title{
Ocorrência de parvovirose e cinomose em cães no Planalto Catarinense
}

\author{
Occurrence of parvovirus and distemper in dogs in the Plateau of Santa Catarina, Brazil
}

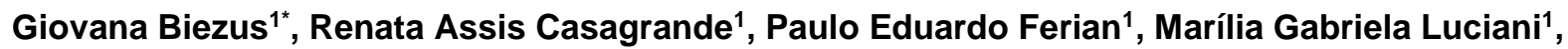 \\ Juliana Regina de Souza ${ }^{2}$, Thierry Grima de Cristo', Suelen Dal Pozo ${ }^{3}$ \& Cristiane Borges Vargas ${ }^{1}$ \\ ${ }^{1}$ Universidade do Estado de Santa Catarina, Lages, SC, Brasil· *Autor para correspondência: giovanavet@live.com. \\ 2 Veterinária Autônoma, Jaraguá do Sul, SC, Brasil. \\ ${ }^{3}$ Veterinária Autônoma, Curitiba, PR, Brasil.
}

Submissão: 17/05/2016 | Aceite: 13/06/2018

\begin{abstract}
RESUMO
Este estudo teve como principal objetivo determinar a ocorrência de parvovirose e cinomose nos cães atendidos no Hospital de Clínicas Veterinárias $(\mathrm{HCV})$ da Universidade do Estado de Santa Catarina (UDESC). Para isso, foram revisados 3198 prontuários de consultas clínicas de cães, arquivados no HCV, do período de fevereiro de 2013 a julho de 2015. Entre os prontuários revisados, 145 (4,53\%) foram diagnosticados com parvovirose (76 [2,38\%]) ou cinomose (69 [2,15\%]). Os sinais clínicos mais encontrados de cada doença foram: para a parvovirose, os sinais gastrointestinais (76 [100\%]), dos quais a hematoquezia foi a mais observada (74 [97,37\%]); para a cinomose, os sinais neurológicos (48 $[69,56 \%]$ ), sendo a mioclonia de maior ocorrência (31 [64,58\%]). Com relação aos resultados do hemograma, a alteração mais encontrada na parvovirose foi a leucopenia por neutropenia e linfopenia (20 $[71,43 \%])$, já na cinomose foi a linfopenia $(28[59,57 \%])$. Também foram observadas a ocorrência de cinomose e parvovirose de acordo com alguns critérios de seleção, como raça, idade, sexo, acesso à rua, contato com outros animais e status de vacinação. Apresentaram maior ocorrência destas doenças os cães jovens, não vacinados e com acesso livre à rua. No âmbito geral, as doenças infecciosas virais na população em estudo se mostraram de baixa ocorrência, sendo a parvovirose a mais relatada.
\end{abstract}

PALAVRAS-CHAVE: vírus, mioclonia, enterite hemorrágica, animais de estimação.

\begin{abstract}
This study determined the occurrence of parvovirus and distemper in dogs treated at the Veterinary Clinics Hospital (HCV) of Universidade Estadual de Santa Catarina (UDESC). For such, 3198 medical records filed in the HCV, from February 2013 to July 2015, were reviewed. From the records, $145(4.53 \%)$ dogs were diagnosed with parvovirus (76 [2.38\%]) or distemper (69 [2.15\%]). The most common clinical signs of parvovirus were gastrointestinal signs $(76[100 \%])$, having hematochezia as the most commonly observed (74 [97.37\%]); for distemper, neurological signs (48 [69.56\%]) were most frequently described and myoclonus had the highest occurrence (31 [64.58\%]). Regarding complete blood count, the most observed variation in parvovirus was leukopenia by neutropenia and lymphopenia (20 [71.43\%]). Distemper showed lymphopenia (28 [59.57\%]). It was also observed that the occurrence of distemper and parvovirus were higher according to some selection criteria: breed, age, outdoor access, having contact with other animals and vaccination status. Young non-vaccinated dogs with outdoor access had the highest occurrence ratio. This study showed that viral infectious diseases presented low occurrence, and parvovirus was the most reported agent.
\end{abstract}

KEYWORDS: virus, myoclonus, hemorrhagic enteritis, pets.

\section{INTRODUÇÃO}

O estudo sobre os aspectos epidemiológicos das doenças infecciosas que acometem os animais domésticos de uma região específica é de grande importância, pois permite a obtenção de informações relevantes com relação aos pacientes e fornece dados sobre determinada moléstia, os quais podem influenciar na formulação de estratégias para o controle, a prevenção e o tratamento das mesmas (ALVES et al. 2005). Os agentes infecciosos virais são responsáveis por um grande número de animais doentes na rotina da clínica veterinária em todo o Brasil, sendo a parvovirose e a cinomose as doenças virais de maior 
ocorrência e responsáveis por um maior número de óbitos nos cães (TRAPP et al. 2010). Acredita-se que esse fator esteja relacionado à baixa adesão aos programas de vacinação (FIGHERA et al. 2008).

A parvovirose é uma doença causada pelo parvovírus canino tipo 2 (PCV-2), um Parvovirus da família Parvoviridae (SYKES 2013), transmitido preferencialmente por via fecal-oral, pelo contato direto com as fezes de cães infectados (MCCAW \& HOSKINS 2006). Os cães que apresentam essa enfermidade desenvolvem sinais clínicos bastante específicos, como enterite hemorrágica, vômitos e desidratação (CASTRO et al. 2007). A suspeita diagnóstica pode ser fortalecida pela presença de leucopenia, neutropenia e/ou linfopenia (SYKES 2013). A diminuição da contagem de leucócitos totais parece estar intimamente relacionada ao aumento da mortalidade causada pelo vírus e está relacionada aos efeitos diretos do vírus sobre os órgãos hematopoiéticos como a medula óssea e o baço (GODDARD et al. 2008).

A infecção pelo PCV-2 é responsável por causar redução da expectativa de vida de cães no Brasil (BENTUBO et al. 2007). Em um estudo realizado no estado do Rio Grande do Sul, a parvovirose correspondeu a $7,2 \%$ das causas de morte de cães necropsiados, ficando atrás somente das doenças neoplásicas e da cinomose (FIGHERA et al. 2008). No Paraná, a parvovirose foi novamente encontrada como a segunda principal causa de óbito e eutanásia, correspondendo a $20 \%$ dos óbitos de uma população hospitalar de cães e gatos (TRAPP et al. 2010). Em São Paulo um estudo apresentou resultados semelhantes, citando a parvovirose entre as principais causas de óbito causada por doenças infecciosas (BENTUBO et al. 2007).

A cinomose é uma doença infecciosa causada pelo vírus da cinomose canina (CDV), um Morbillivirus da família Paramyxoviridae, que é responsável por causar sinais clínicos neurológicos, gastrointestinais, respiratórios, dermatológicos e oftálmicos (GREENE \& APPEL 2006). Os sinais clínicos neurológicos são variáveis, sendo a mioclonia e as convulsões os mais comuns (SILVA et al. 2007). Muitas vezes os sinais clínicos são graves e irreversíveis, podendo causar a morte do paciente canino (FIGHERA et al. 2008), por isso, é considerada uma doença infecciosa letal em cães domésticos (DEEM et al. 2000). No Brasil os estudos até então realizados demonstram alta ocorrência dessa doença e que a mesma pode ser considerada endêmica no país (TRAPP et al. 2010, LIMA \& LALLO 2013, LÚCIO et al. 2014). Em estudos realizados na região sul do país, a cinomose ficou entre as principais causas de óbitos em cães submetidos a necropsia (HEADLEY \& GRAÇA 2000, FIGHERA et al. 2008). Na região metropolitana de São Paulo, a cinomose também foi relatada como a principal causa de óbito e diminuição da expectativa de vida dos cães (BENTUBO et al. 2007).

Baseado no fato de que, na literatura consultada, não consta nenhum estudo epidemiológico sobre as infecções virais que acometem cães da região do Planalto Catarinense, o objetivo deste trabalho foi determinar a ocorrência de cinomose e parvovirose nos cães atendidos no Hospital de Clínicas Veterinárias $(\mathrm{HCV})$ da Universidade do Estado de Santa Catarina (UDESC). Além disso, objetivou-se determinar quais as suas principais formas de apresentação clínica e alterações hematológicas encontradas nesses animais.

\section{MATERIAL E MÉTODOS}

Foram revisados os prontuários clínicos dos cães atendidos no pronto-atendimento, pela equipe de médicos veterinários residentes do Hospital de Clínicas Veterinárias (HCV) da Universidade do Estado de Santa Catarina (UDESC), no período de fevereiro de 2013 a julho de 2015, totalizando 3198 prontuários. Foram incluídos neste estudo cães oriundos de municípios da região do Planalto Catarinense: Capão Alto, Correia Pinto, Lages, Otacílio Costa e São Joaquim. Com os dados obtidos, foram selecionados os que possuíam diagnóstico clínico de cinomose ou parvovirose e compilados em tabela (Excel). Fizeram parte do estudo os casos que apresentaram um ou mais sinais clínicos da doença, que foram fundamentados a partir de exames laboratoriais como hemograma e imunoensaio cromatográfico para detecção de antígeno do parvovírus canino e da cinomose canina (Bioeasy Anigen Rapid CPV ${ }^{\circledR}$ ). Pacientes em que o diagnóstico clínico não condizia com as alterações laboratoriais e sinais clínicos esperados para a doença, assim como pacientes com comorbidades que poderiam influenciar no diagnóstico final, foram excluídos da pesquisa.

Junto com o diagnóstico clínico, dados complementares da resenha e história clínica como raça, idade, sexo, utilização de vacinas, modo de vida do animal, sinais clínicos apresentados e o desfecho da doença foram obtidos. Os cães foram classificados da seguinte maneira: quanto à raça, foram classificados como sem raça definida (SRD) ou com raça definida; com relação ao gênero foram classificados como macho ou fêmea; quanto à faixa etária foram divididos em menos de 1 ano, entre 1 e 7 anos e mais de 7 anos, seguindo o critério de classificação para cães geriátricos acima de 7 anos (FORTNEY 2008), quanto à utilização de vacinas, foram classificados em adequadamente vacinados ou não, sendo considerado adequado todos os animais submetidos ao esquema completo da vacinação, incluindo vacina da raiva e a 
vacina óctupla $(\mathrm{V}-8)$ ou déctupla $(\mathrm{V}-10)$; se possuem acesso livre à rua ou não; se possuem contato direto com outros cães; segundo o desfecho da doença, se a mesma foi responsável pelo óbito do animal ou não, seja o óbito em decorrência da doença ou por meio de eutanásia.

Após a classificação, foi obtida a ocorrência de cada enfermidade para cada um dos critérios de classificação citados acima, assim como a obtenção das principais alterações hematológicas e sinais clínicos encontrados em cada doença. Os diagnósticos aqui citados foram realizados pelos médicos veterinários residentes responsáveis pelo atendimento, em conjunto com um médico veterinário supervisor experiente, e fundamentado em achados clínicos e exames laboratoriais.

\section{RESULTADOS}

Dos 3198 atendimentos de cães, $145(4,53 \%)$ foram diagnosticados com parvovirose (76 [2,38\%]) ou cinomose (69 [2,15\%]). Destes, $88(60,69 \%)$ não possuíam raça definida, enquanto $57(39,31 \%)$ possuíam. Destes, 11 cães eram da raça Pinscher (18,64\%); oito (13,55\%) Rottweiler; seis (10,53\%) da raça Labrador; cinco $(8,77 \%)$ da raça Poodle; e 27 (45,76\%) correspondem a outras raças que foram menos prevalentes, sendo elas o American Staffordshire Terrier, Pastor Alemão, Dogue Alemão, Pointer Inglês, Dachshund, Shih-tzu, Pit Bull, Buldogue Francês, Fila Brasileiro, Australian Cattle Dog e Chow-chow. Com relação à idade, 108 (71,05\%) cães apresentavam menos de 1 ano, 36 (24,82\%) tinham entre 1 e 7 anos e um $(0,69 \%)$ acima de 7 anos. Quanto ao gênero foram encontrados $75(51,72 \%)$ machos e $70(48,68 \%)$ fêmeas.

Entre os prontuários analisados, $112(73,79 \%)$ cães possuíam contato direto com outros animais da mesma espécie, enquanto $38(26,21 \%)$ não. Quanto ao uso de vacinas, 132 cães $(91,03 \%)$ não foram vacinados adequadamente. Dos animais que contraíram doenças infecciosas virais, $94(64,83 \%)$ não possuíam acesso livre à rua, enquanto $51(35,17 \%)$ sim. O desfecho dessas doenças para 29 cães (20\%) foi o óbito. A ocorrência de cada doença também foi obtida quanto aos critérios de classificação. Os resultados podem ser visualizados de maneira global na Tabela 1.

Tabela 1. Ocorrência de parvovirose e cinomose quanto aos critérios de classificação dos casos clínicos estudados.

Table 1. Occurrence of parvovirus and distemper considering the classification criteria of the studied clinical cases.

\begin{tabular}{llcc}
\hline Critérios de classificação & & $\begin{array}{c}\text { Parvovirose } \\
\text { Número de casos (\%) }\end{array}$ & $\begin{array}{c}\text { Cinomose } \\
\text { Número de casos (\%) }\end{array}$ \\
\hline Raça & Sem raça definida & $46(60,53)$ & $42(60,87)$ \\
& Com raça definida & $30(39,47)$ & $27(39,13)$ \\
Idade & Menos de 1 ano & $69(90,79)$ & $39(56,52)$ \\
& Entre 1 e 7 anos & $7(9,21)$ & $29(42,03)$ \\
& Mais de 7 anos & - & $1(1,45)$ \\
Gênero & Macho & $36(47,37)$ & $39(56,52)$ \\
& Fêmea & $40(56,53)$ & $30(43,48)$ \\
Uso adequado de vacinas & Sim & $6(7,9)$ & $7(10,15)$ \\
& Não & $70(92,10)$ & $62(89,85)$ \\
Acesso livre à rua & Sim & $59(77,63)$ & $34(49,27)$ \\
& Não & $17(22,37)$ & $35(50,73)$ \\
Contato com outros cães & Sim & $55(72,37)$ & $52(75,36)$ \\
& Não & $21(27,63)$ & $17(24,64)$ \\
Óbito & $9(11,84)$ & $20(28,98)$ \\
\hline
\end{tabular}

Todos os cães diagnosticados com parvovirose apresentaram sinais gastrointestinais (76 [100\%]) como anorexia, êmese, diarreia, diarreia associada à hematoquezia. Somente 41 (53,95\%) apresentaram sinais hemodinâmicos na forma de desidratação decorrente da grande perda de fluidos pela êmese e diarreia, associada à anorexia. Os sinais clínicos mais identificados podem ser visualizados na Tabela 2.

Com relação aos sinais clínicos apresentados pelos cães diagnosticados com cinomose: 48 (69,56\%) apresentaram sinais clínicos neurológicos como mioclonia, ataxia, tetraparesia, convulsão, tremores de intenção e/ou alterações comportamentais como vocalização e/ou agressividade; 40 (57,97\%) apresentaram 
sinais oftálmicos como conjuntivite bilateral com secreção purulenta; 36 (52,17\%) sinais clínicos gastrointestinais como anorexia, êmese e/ou diarreia; 28 (40,58\%) sinais clínicos respiratórios como tosse, espirros, dispneia e/ou secreção nasal bilateral de aspecto seroso ou purulento; 22 (31,88\%) sinais clínicos dermatológicos como pústulas e/ou hiperqueratose de plano nasal e coxins. Os sinais clínicos mais identificados podem ser visualizados na Tabela 3.

Tabela 2. Ocorrência dos sinais clínicos em cães diagnosticados com parvovirose de acordo com o sistema orgânico afetado.

Table 2. Occurrence of clinical signs in dogs diagnosed with parvovirus according to the affected organic system.

\begin{tabular}{lll}
\hline Sistema Orgânico & Sinais clínicos & Número de casos (\%) \\
\hline Gastrointestinal & Diarreia associada à hematoquezia & $74(97,37)$ \\
& Êmese & $72(94,77)$ \\
& Anorexia & $57(75)$ \\
Cardiovascular & Diarreia & $2(2,63)$ \\
& Desidratação & $41(100)$ \\
\hline
\end{tabular}

Para a realização do diagnóstico $78(53,79 \%)$ cães foram submetidos à coleta de sangue e realização de hemograma, desses $47(60,25 \%)$ com cinomose e $31(39,74 \%)$ com parvovirose. As alterações encontradas foram as seguintes: a leucopenia por neutropenia e linfopenia foi o achado de maior ocorrência na parvovirose (20 [71,43\%]); e a linfopenia foi predominante nos cães com cinomose (28 [59,57\%]). Foram submetidos à realização de imunoensaio cromatográfico para detecção de antígeno do parvovírus canino e do vírus da cinomose 47 cães, destes 12 (25,53\%) com cinomose e 35 (74,47\%) com parvovirose.

Tabela 3. Ocorrência dos sinais clínicos em cães diagnosticados com cinomose de acordo com o sistema orgânico afetado.

Table 3. Occurrence of clinical signs in dogs diagnosed with distemper according to the affected organic system

\begin{tabular}{llc}
\hline Sistema Orgânico & Sinais clínicos & Número de casos (\%) \\
\hline Sistema nervoso & Mioclonia & $31(64,58)$ \\
& Ataxia & $22(45,83)$ \\
& Tetraparesia & $15(31,25)$ \\
& Convulsão & $8(16,67)$ \\
& Tremores de intenção & $8(16,67)$ \\
Oftálmico & Alterações comportamentais & $4(8,33)$ \\
Gastrointestinal & Conjuntivite & $40(100)$ \\
& Anorexia & $21(58,33)$ \\
& Émese & $20(55,55)$ \\
Respiratório & Diarreia & $16(44,44)$ \\
& Secreção nasal & \\
& Tosse & $21(75)$ \\
Espirro & $20(71)$ \\
Dermatológico & Dispneia & $5(17,86)$ \\
& Pústulas & $3(10,71)$ \\
& Hiperqueratose de plano nasal e coxins & $16(72,73)$ \\
& & $12(54,54)$ \\
\hline
\end{tabular}

\section{DISCUSSÃO}

Dos prontuários avaliados somente, 4,53\% apresentaram o diagnóstico de parvovirose ou cinomose, dados que diferem de outros trabalhos realizados no Brasil, que apresentaram maior ocorrência, 19,6\% e $43,18 \%$ respectivamente (FIGHERA et al. 2008, TRAPP et al. 2010). A baixa ocorrência aqui encontrada é explicada pela ausência de área de isolamento para o internamento de animais com doenças infectocontagiosas no HCV, causando assim uma diminuição pela procura desses serviços e influenciando diretamente no número de atendimentos.

Pode-se também observar que a ocorrência das doenças virais avaliadas no estudo é maior com 
relação a alguns critérios de seleção. Cães com menos de 1 ano e não vacinados ou sem o esquema completo de vacinação apresentaram maior ocorrência, dados que também foram obtidos em outros estudos (DEZENGRINI et al. 2007, FIGHERA et al. 2008). Cães SRD estiveram em maior número entre os animais doentes, porém não é um critério de classificação que pode ser avaliado com segurança, pois a proporção de cães SRD atendidos no HCV é maior que de cães com raça definida.

A parvovirose apresentou maior ocorrência que a cinomose entre os cães atendidos no HCV e que fizeram parte deste estudo. Com relação aos critérios de seleção de cães com menos de 1 ano e que não possuíam protocolo adequado de vacinação apresentaram maior ocorrência da doença, dados que também foram obtidos em outros estudos (BENTUBO et al. 2007, FIGHERA et al. 2008). Dados similares foram obtidos em um estudo realizado no estado do Espírito Santo, no qual somente $38 \%$ dos proprietários relataram administrar a vacina óctupla $(\mathrm{V}-8)$ ou déctupla $(\mathrm{V}-10)$ que protegeria os cães contra 0 desenvolvimento dos sinais clínicos da parvovirose e cinomose (SUHETT et al. 2013). Em uma avaliação imuno-histoquímica em cães necropsiados com suspeita de parvovirose, observou-se que os cães positivos pertenciam a faixa etária de até 11 meses (OLIVEIRA et al. 2009). Além disso, observou-se em outro estudo que a ausência de protocolo correto de vacinação associada à soronegatividade ou a baixos títulos de anticorpo contra o vírus pode ser um fator importante na conservação do vírus na população (STROTTMANN et al. 2008).

Outros dois critérios de seleção foram bastante expressivos quanto à ocorrência de parvovirose: o acesso livre à rua e contato com outros cães. Em um dimensionamento da população de cães e gatos do estado de São Paulo, observou-se que uma grande parcela dos cães possuíam acesso livre à rua, e por esse motivo constituem uma população de risco para o desenvolvimento de doenças infectocontagiosas (ALVES et al. 2005). Porém, outro estudo não demonstrou diferença significativa com relação à soroprevalência para o PCV entre os cães que têm contato com outros animais da mesma espécie e os que não têm (DEZENGRINI et al. 2007).

Os sinais clínicos gastrointestinais encontrados nos casos de parvovirose estudados estão de acordo com os descritos na literatura (CASTRO et al. 2007), assim como as alterações hematológicas, em que a leucopenia foi a mais observada. A leucopenia causada por intensa neutropenia e linfopenia é considerada indicadora de prognóstico e está diretamente relacionada com a gravidade da doença (GODDARD et al. 2008).

Por sua vez, a cinomose foi a segunda mais relatada. Realizando-se uma avaliação global quanto à ocorrência de cães com cinomose, com relação ao número total dos casos avaliados, pôde-se observar que a mesma é baixa $(2,15 \%)$. Com exceção de um estudo conduzido no estado do Paraná que demostrou prevalência semelhante (2,07\%) (BORBA et al. 2002), todos os estudos avaliados resultaram em maior ocorrência, de 12,4 e 23,18\% (FIGHERA et al. 2008, TRAPP et al. 2010).

Com relação aos critérios de classificação, os cães com menos de 1 ano, machos e não vacinados apresentaram maior ocorrência dessa doença. Em um estudo epidemiológico realizado durante um surto de cinomose em cães domésticos em Indiana, Estados Unidos, foram caracterizados fatores de risco, e constatou-se que 93,8\% dos casos aconteceram por falta de vacinação (PATRONEK et al. 1995). Dados similares foram obtidos, nos quais $89,85 \%$ não foram vacinados adequadamente. A ocorrência de cinomose em cães com acesso livre à rua foi praticamente idêntica aos que não possuíam acesso, somente um caso a mais. Em um levantamento epidemiológico conduzido no estado de Pernambuco, também não foi encontrada diferença significativa (LÚClO et al. 2014).

Quanto aos sinais clínicos, os sinais neurológicos foram os mais relatados, a exemplo de um estudo conduzido por SILVA et al. (2007) em que a mioclonia foi mais ocorrente. A respeito das alterações hematológicas, a linfopenia foi a alteração mais encontrada. Este dado confere com os resultados encontrados em um estudo no qual foram avaliados perfil hematológico de cães com cinomose acometendo o sistema nervoso (TUDURY et al. 1997).

Para 29 cães $(19,08 \%)$ o desfecho dessas doenças foi o óbito. Tanto a parvovirose como a cinomose são conhecidas por causar uma drástica redução na expectativa de vida dos cães causando um elevado número de mortes entre os animais doentes (FIGHERA et al. 2008). Em uma avaliação sobre a expectativa de vida de cães da região sudeste do país, observou-se que a idade média de vida dos animais diagnosticados com cinomose e parvovirose era de 12 meses (BENTUBO et al. 2007). Porém o número de óbitos no presente trabalho pode ter sido subestimado, devido ao fato de que muitos pacientes não retornam ao HCV para o controle da doença ou são internados em outras clínicas da cidade por não ser permitido o internamento de animais com doenças infectocontagiosas no HCV, além de que o óbito do animal pode ter ocorrido em casa, sem que o médico veterinário seja avisado. 


\section{CONCLUSÃO}

A ocorrência de parvovirose e cinomose foram baixas na população estudada. Animais que se enquadravam nas categorias jovens, não vacinados e que possuíam acesso livre à rua foram as categorias com maior ocorrência dessas doenças.

A ausência de vacinação ou a utilização de protocolos incorretos para a mesma foi o principal fator visualizado na ocorrência de ambas as doenças, o que demonstra a necessidade de maior conscientização da população e enfatiza a falta de conhecimento ou negligência dos proprietários quanto aos cuidados com o seu animal de estimação.

Apesar da ocorrência dessas doenças serem baixas nos cães atendidos no HCV, estes resultados não podem ser extrapolados para a população de cães do Planalto Catarinense, devido à amostra representar somente uma pequena parcela da população.

\section{REFERÊNCIAS}

ALVES MCGP et al. 2005. Dimensionamento da população de cães e gatos do interior do Estado de São Paulo. Revista de Saúde Pública 39: 891-897.

BENTUBO HDL et al. 2007. Expectativa de vida e causas de morte em cães na área metropolitana de São Paulo (Brasil). Ciência Rural 37: 1021-1026.

BORBA TR et al. 2002. Cinomose: dados epidemiológicos Maringá-PR (1998-2001). Iniciação Científica - Cesumar 04: 53-56.

CASTRO TX et al. 2007. Clinical and epidemiological aspects of canine parvovirus (CPV) enteritis in the State of Rio de Janeiro: 1995 - 2004. Arquivo Brasileiro de Medicina Veterinária e Zootecnia 59: 333-339.

DEEM SL et al. 2000. Canine distemper in terrestrial carnivores: a review. Journal of Zoo and Wildlife Medicine 31: 441451.

DEZENGRINI R et al. 2007. Soroprevalência das infecções por parvovírus, adenovírus, coronavírus canino e pelo vírus da cinomose em cães de Santa Maria, Rio Grande do Sul, Brasil. Ciência Rural 37: 183-189.

FIGHERA RA et al. 2008. Causas de morte e razões para eutanásia de cães da Mesorregião do Centro Ocidental RioGrandense. Pesquisa Veterinária Brasileira 28: 223-230.

FORTNEY WD. 2008. Geriatria e senilidade. In: HOSKINS JD. Geriatria e gerontologia do cão e do gato. 2.ed. São Paulo: Roca. p.1-5.

GREENE CE \& APPEL MJ. 2006. Canine Distemper. In: GREENE CE. Infectious disease of the dog and cat. 3.ed. St. Louis, Missouri: Elsevier. p.25-41.

GODDARD A et al. 2008. Prognostic usefulness of blood leukocyte changes in canine parvoviral enteritis. Journal of Veterinary Internal Medicine 22: 309-316.

HEADLEY SA \& GRAÇA DL. 2000. Canine distemper: epidemiological findings of 250 cases. Brazilian Journal of Veterinary Research and Animal Science 37: 136-140.

LIMA RSC \& LALLO MA. 2013. Public survey of knowledge concerning canine distemper and protective measures. Revista Brasileira de Ciência Veterinária 20: 213-215.

LÚCIO EC et al. 2014. Análise epidemiológica da infecção pelo vírus da cinomose, em cães do município de Garanhuns, Pernambuco, Brasil. Semina: Ciências Agrárias 35: 1323-1330.

MCCAW DL \& HOSKINS JD. 2006. Canine viral enteritis. In: GREENE CE. Infectious disease of the dog and cat. 3.ed. St. Louis, Missouri: Elsevier. p.63-70.

OLIVEIRA EC et al. 2009. Análise imuno-histoquímica de cães naturalmente infectados pelo parvovírus canino 1. Pesquisa Veterinária Brasileira 29: 131-136.

PATRONEK GJ et al. 1995. Canine distemper infection in pet dogs: II. A case-control study of risk factors during a suspected outbreak in Indiana. Journal of the American Animal Hospital Association 31: 230-235.

SILVA MC et al. 2007. Aspectos clinicopatológicos de 620 casos neurológicos de cinomose em cães. Pesquisa Veterinária Brasileira 27: 215-220.

STROTTMANN DM et al. 2008. Diagnóstico e estudo sorológico da infecção pelo parvovírus canino em cães de Passo Fundo, Rio Grande do Sul, Brasil. Ciência Rural 38: 400-405.

SUHETT WG et al. 2013. Percepção e atitudes de proprietários quanto a vacinação de cães na região sul do estado do Espírito Santo - Brasil. Brazilian Journal of Veterinary Research and Animal Science 50: 26-32.

SYKES JE. 2013. Canine parvovirus infections and other viral enteritides. In: SYKES JE. Canine and feline infectious diseases. St. Louis, Missouri: Elsevier. p.141-151.

TRAPP SM et al. 2010. Causas de óbito e razões para eutanásia em uma população hospitalar de cães e gatos. Brazilian Journal of Veterinary Research and Animal Science 47: 395-402.

TUDURY EA et al. 1997. Observações clínicas e laboratoriais em cães com cinomose nervosa. Ciência Rural 27: 229235. 